Валентина Николаевна Калиновская

Россия, Институт тингвистических исследований РАН

Ольга Альбертовна Старовойтова

Россия, Санкт-Петербургский государственный университет

\title{
О кавычках, скобках и не только... в русском тексте XIX в. Часть І. К вопросу о роли «тире» в текстах периодической печати
}

Ключевые слова: русский язык, русский язык XIX века, текст, пунктуация, тире. Key words: the Russian language, the $19^{\text {th }}$-century Russian language, text, punctuation, dash.

\begin{abstract}
The history of punctuation marks in a certain sense reflects the history of the Russian literary text as a structurally organized unity for the expression of the author's intention. It is considered that in the $19^{\text {th }}$-century Russian punctuation attracted much less attention than disordered spelling. Therefore, it seems important to analyze the structural and semantic significance of such a punctuation mark as dash in the $19^{\text {th }}$-century Russian text, which ensures the implementation of logical, semantic, emphasis-emphasizing, emotionally expressive functions. The conclusions presented in the article are based on observations of the use of the aforementioned punctuation mark in deep connection with meaning and stylistics in texts of a specific genre.
\end{abstract}

Изучать исторически что-либо - значит изучать в движении.

Л.С. Выготский

В отечественной лингвистике первые опыты теоретически осмыслить пунктуацию как систему особых графических знаков, применяемых в письменной речи, связывают с именами М.В. Ломоносова, А.А. Барсова, Ф.И. Буслаева, Н.И. Греча, А.Х. Востокова, Я.К. Грота; в своих работах эти ученые касались 
в основном вопросов классификации знаков препинания с точки зрения их положения в текстовом пространстве («основные» и «вспомогательные»), установления их функциональной значимости. Делались попытки терминологически определить то или иное понятие; так знак препинания «тире» впервые упоминается в «Российской грамматике» А.А. Барсова, получая название «молчанка» (употреблялось параллельно с «Рause»). Современные исследователи, опираясь на исследования В.Ф. Ивановой, полагают, что Н.М. Карамзин вовсе не был изобретателем тире (как считалось долгое время), но мог способствовать популярности и закреплению функций этого знака благодаря своей писательской практике [Švarckopf 1997: 562].

Несмотря на то, что вопросы, связанные с пунктуацией, обсуждались в трудах лингвистов XVIII-XIX вв., они не были в центре внимания и не получили такой глубокой проработки, как проблемы орфографии на данном этапе развития русской филологической мысли. Широкое понимание пунктуации как особой семиотической системы, влияющей на восприятие письменного/ печатного текста, складывается уже в следующем столетии.

Возврат к теме пунктуации в научной среде был положен работой И.А. Бодуэна де Куртене (1913), где он проводил дифференциацию пунктуации в узком смысле (собственно знаки препинания - точка, двоеточие, точка с запятой, запятая) и в «широком» смысле («разделение книги на отделы, на главы, на параграфы, статьи», абзацы, «отделительные черты», тире, пробелы, скобки, «выноски внизу страниц или в конце книги», кавычки, апостроф) [Boduèn de Kurtene 1963: 238-239].

Современные исследователи полагают, что принятая в настоящее время система употребления знаков препинания во многом сложилась уже в XIX в., и считают «неоспоримой роль мастеров-печатников в пропаганде и внедрении в массовую практику пунктуационных инноваций» [Orehova 2000: 109].

В настоящей статье не ставится задача проанализировать весь комплекс проблем, связанных с употреблением пунктуационных знаков в письменном (печатном) тексте XIX в. Однако на некоторые особенности функционирования такого знака, как «тире», в текстовом пространстве данного исторического периода хотелось бы обратить внимание.

Эта пунктуационная графема для XIX в. была явлением относительно новым - ее присутствие в русском тексте обнаруживается впервые в 60-е гг. XVIII в., в последующую эпоху этот знак уже активно употребляется в двух основных функциях: для графической организации и для членения письменного (печатного) текста ${ }^{1}$.

1 Данные функции выделяются при определении содержания термина пунктуация, под которой понимается «система обязательных графических внеалфавитных знаков, составляющих вместе с графикой и орфографией совокупность основных средств письменного языка» [Švarckopf 1988: 120]. 
Примеры употребления тире в тексте XIX в., которые рассматриваются в первой части данной статьи, на наш взгляд, характеризуются совмещением указанных функций. Тире использовалось в газетном или журнальном тексте, в частности в информационных разделах периодического издания: «Газета начинает рассказывать новости, чего нельзя было представить ранее. Понятие новости так же важно для понимания осуществления медиа события...» [Skripčenko 2016: 23]. Такие разделы, как «Внутренние известия» и «Иностранные известия», отличали, прежде всего, регулярные периодические издания, в которых новостная информация, доставляемая из-за границы или из разных уголков обширной территории России, составляла существенную часть общего объема текста. Журнальные/газетные новости были значимым элементом того самого «журнализма», который, по мнению современников, к середине века уже «распространяется на все формы словесности», когда «мысль подчинена текущим обстоятельствам», «форма приноровлена требованиям минуты» [Kireevskij 1911: 122]. По мнению исследователей истории масс-медиа, с появлением первых газет возникла естественная потребность в информации: «происходящие события стали общественно значимы для читающей публики Нового времени» [Skripčenko 2016: 4]; «на первый план выходит событие. Именно событийное наполнение медиа-пространства, препарирование и выбор нужного ракурса события выстраивает картину и повестку дня» [Skripčenko 2016: 4], освещаемую периодической печатью.

Одним из способов подачи информации в периодических изданиях было графическое оформление миниконтекста в самостоятельный абзац с помощью тире; несколько следующих один за другим таких абзацев в какой-то степени были прообразом «новостной ленты» современных масс-медиа. Постановка тире в начале абзаца в сочетании с лексико-грамматическими средствами позволяли акцентировать внимание на событии или факте, представляющих содержание новости, и обстоятельствах их происхождения.

Тире как графический маркер новостной информации может указывать на:

1. Место / место + деятель: - В Великобританіи находятся 103 канала, кои вст вмгсть составляют в длину 2682 мили [каждая в 754,5 наших сажени, или не с большим полторы верстьл리 (СМ: 43); - Во Франиіи Г. Жюліа-Фонтанель и в Германіи Г. Швейнсберг пробовали выюжимать из виноградных косточек масло (СМ: 2).

2. Лицо-деятель: - Г. Бонафу предлагает пробовать в Европь образ воздъльванія шелковичнаго дерева, употребляемый с давних времен Китайцами и введенный уже с успюхом в земледгліе Соединенных Штатов съверной Америки (СМ: 11).

3. Дату / дату + источник: - Еще в 1828 году писали в разных Франиузских журналах, что Барон Серрет, Брюжскій помъщзк (в Голландіи, не далеко от

\footnotetext{
2 Примеры из дореформенных источников приводятся с изъятием только конечного <ъ>.
} 
Остенде), успюл развести у себя Американское растъніе Myrica pensylvanica и получить из него воск подобный пчелиному (CМ: 2); - Генваря 12 дня 1829 года Министерством Внутренних Дгл вылдна привиллегія на десять льт сыновьям Механика Уигофа, Александру и Федору Ушгофам, на изобргттенную ими машину для разрґзыванія или разпластывванія кож на два и болґе листов. На устроеніе упомянутой машины в надлежащем видъ Высочайше повельно выдать [и выдано] Уигофам в ссуду 5ооо рублей (СМ: 17).

4. Источники самого разного типа:

4.1. печатное издание: - Издателем сей газеты выписано было в 1823 году из Нерчинских заводов не большое количество стомен Гималайскаго ячменя, очень близкаго по виду к пшенииг, для раздачи оных на пробный поств в окрестностях С. Петербурга (СМ: 10); - В журналь полезных свъдъьній сообщены сльдующія извъстія о самьхх больших алмазах... (СМ: 12).

4.2. текст: - В отчетг Министерства Внутренних дгол за 1828 год показано, что Коммиссія, учрежденная для точнаго опредъленія въсов и мґр, в 1828 году окончила возложенное на нее порученіе (СМ: 2).

4.3. лицо: - Г. Д’Арсет, извъстный Парижскій Химик, прогзжая в 1827 году чрез Шодъ-Эгю (в Капталь), расказал г. Фельжеру, хозяину ванн при тамошних тепльх ключах, о способг коим можно высижсивать ијыплят искуственною теплотою (СМ: 11-12).

В лексико-грамматической конструкции начальной текстовой фразы допускается варьирование в рамках формирующегося стандарта: - Из Kяхть пишут; - Оттудеже пишут; - Из Тифлиса увъдомляют; - Из Гамбурга, Лондона, Амстердама и Парижа постоянно приходят извъстія; - По извтостіям из Москвы...

С помощью тире также могла производиться рубрикация раздела: тогда оно служило сигналом перехода к новому событию в рамках обсуждаемой темы. Так, например, оформлялся раздел «Моды» в отделе Смесь «Библиотеки для чтения»: здесь тире маркирует каждый новый абзац, посвященный какойлибо новости из сферы моды:

- В иляпках бастовых, paille de riz, поля бывают немного отвернутые, убранные газовыми лентами [...]

— Шарфы опять начинают входить в употребленіе [...] (В: 70).

Или:

- Три вещчи нынче в величайшей модъ в Парижг, полька, натуральные ивъты на головъ, и платья с огромными клґтками [...]

- В Парижг теперь все кльттчатое, и кльттки - огромнғийшия [...] это безобразно, но если в Парижгь находят такія матеріи прекрасными, то вскорг и у нас онг будут господствовать повсемғстно (В: 146-147).

В приведенных примерах мы имеем дело с употреблением тире для структуризации текста, характеризующегося смысловой целостностью (новости моды), фрагментация которого обусловлена событиями, заслуживающими 
как раздельно оформленного сообщения, так и выделения авторского комментария (последний пример) ${ }^{3}$.

Изменение культурной парадигмы в России XIX в., о которой писали в середине века: «В наше время изящную словесность заменила словесность журнальная» [Kireevskij 1911: 122], - дало толчок новым тенденциям в употреблении знаков препинания. Общественно значимые для читающей публики события в изданиях XIX в. представлены в авторских статьях разного объема - от небольшой вступительной статьи к номеру до значительной по объему проблемной/аналитической. И здесь также можно наблюдать случаи использования знака «тире», которые по функции совпадают с рассмотренным выше назначением знака в новостных разделах - как способ членения текста и подачи новой/дополнительной информации, нового факта нового «голоса» по теме или на тему чего-л.: - Недавно прочли мы в одной Санкпетербургской газете, что император Наполеон имеет мысль созвать, для решения Польскаго и других вопросов, Европейский конгресс (А: 50).

Однако газетный/журнальный текст активно расширяет спектр возможностей для использования пунктуационных знаков. Поскольку публицистика в России XIX в. в отсутствие социальных институтов, обеспечивающих наличие собственно политической жизни, была трибуной выражения общественно-политических взглядов и идейной борьбы, тексты должны были обладать определенным прагматическим потенциалом, чтобы произвести впечатление на читателя, привлечь его на свою сторону. Базовая коммуникативная интенция автора публицистического материала реализовывалась с помощью ряда стратегий, в т.ч. диалогизации текста.

Идея журналистики как продолжения беседы, считающаяся традиционной британской моделью журнализма [Samarcev 2007: 16], не была чужда текстам российских изданий XIX в. Намерение автора устанавливать контакт с читателем реализуется в т.ч. с помощью пунктуационного знака «тире».

Тире отделяет от предшествующего текста/части предложения:

1. предложение, начинающееся с частиц «да» и «нет», которыми автор как будто отвечает читателю, предугадывая его возможную реплику;

2. вопросительное предложение, которое в зависимости от авторского намерения может быть вопросом, реально обращенным к читателю, или же риторическим, усиливающим выразительность текста: - Cтоим ли мы все как один человек? (А: 50); Если бы удержали и возбранили, то дух жизни был бы для нас невозвратно потерян, - а что̀ же тело без жизни? (A: 99);

3 Интересно, что функционально и семантически сходным оказывается употребление тире для выделения нового смысла слова в структуре словарной статьи, которое известно как «тире Срезневского». Графический знак, впервые употребленный российским филологом в «Материалах для словаря...», оказался настолько удачным, что прочно вошел в лексикографическую практику для демонстрации лексико-семантических вариантов слова (особенно в исторических словарях). 
3. предложение, представляющее собой метатекстовый комментарий, который также ориентирован на «беседу» с читателем: - Если бы пожелали знать наше частное, личное мнение, то мыл... (A: 30); Но мы увлеклись в сторону [...], - обратимся к нашей живой исторической дтьйствительности (А: 75); Подробное, научное развитіе этого взгляда принял на себя наш многоуважаемый ученый, В.Н. Лешков [...], - а мы ограничимся здъсь сльдующими, менте общими, менее абстрактными замъчаніями (А: 88);

4. предложения-умозаключения, являющиеся выводом из предшествующего рассуждения: Если сльдить за ходом событій по газетам иностраннылм и нашим, то невольно представляется, будто объ стороны играют в жмурки [...]. - Отсюда этот ряд постоянных недоразумъній, нечаянностей... (A: 59); Но это право есть нравственное право самой народной личности, а нисколько не той политической, государственной личности, или, правильнъе, формаціи [...] -, если только сама эта формація уже не сплотилась в одно органическое духовное иъълое (А: 33).

5. Принципиально важным является маркирование в тексте предложений, содержащих эксплицитно выраженную позицию автора в отношении рассматриваемой проблемы: - Mbl должны отвечать только пред собственною своею народною совестью... (A: 49); - Этим господам несравненно привольнъе пребывать в каком-то смутном состояніи, в какой-то сторой неопредгленности мысли и чувства... (А: 701).

В данном случае до́лжно говорить не столько о структурной, сколько об эмфатической (эмоционально-выделительной) функции знака препинания: читатель, оставаясь «немым наблюдателем», тем не менее не должен остаться наблюдателем безучастным.

Подобная функция, на наш взгляд, ярче всего проявляется в использовании «тире» внутри предложения, это является одним из самых эффективных способов «актуализации читателя»: «Актуализация читателя [...] соответствует реальности бытия текста в обществе, где его „потребление” многократно превышает „исполнение” и где работают над пониманием и расшифровкой текста» [Dibrova 1998: 253]. Расшифровка текста читателем в случае использования тире значительно упрощается: пунктуационный знак является сигналом контактоустановления и, какой бы конкретно ни была интенция автора $^{4}$, читатель на этот сигнал реагирует.

Тенденция членения текста, рассматриваемая в настоящей статье, достигла своего апогея в случаях использования тире как знака парцелляции (вместо принятой в современной традиции точки) для усиления акцентирования элементов речи. Обращает на себя внимание разная степень связи частей, разделяемых тире. В отличие от классификации А.П. Сковородникова, который выделяет

4 Оставляем за скобками традиционные случаи постановки тире для выделения вставных конструкций. 
слабую парцелляцию только на уровне бессоюзного сложного предложения [Skovorodnikov 1978], предлагаем оперировать тремя ступенями в пределах простого предложения:

1. слабая (парцеллят с функцией дополнительной информации): поводов $\kappa$ постоянному раздраженію и неудовольствію жителей на администрацію должно убавиться - едвали не на половину (А: 45); необходимо, чтоб крестьянин понимал и Государев указ, и внушеніе Русской власти - вполнг отчетливо, без недоразумъній (А: 114);

2. средняя (парцеллят, несмотря на его некоторую грамматическую автономность, несет содержательную нагрузку; часто расположен в начале фразы): И так - кому принадлежит Русская земля? (А: 89); Сльдовательно какое же главнтйшее и единственное условіе успеха для нас в предстоящей борьбъ? (А: 97); Конечно - это свои; необразованное мужичье, коснъющее в предразсудках (А: 698);

3. сильная (разрывающая семантические и грамматические связи): народ, сложился в гражданское общество, получил свое личное опредгленіе и в свою очередь наложил на это пространство земли - печать своей личности (A: 88); Правительство в правь ожидать и без сомнгнія ожидает от общества содпйствія иного рода (А: 116); если и упомянул <Мельгунов> про Русскаго человъка, так только для того, чтобы назвать его тут же кстати - плутом?! (А: 698); Таким безобразным смғшеніем, такою путаницей понятій особенно страждет наша Россійская общественная современность, прикрывая плащем прогресса, гуманности и т.д. - свою тощую логику (А: 701).

Как показал исследованный материал, такое нарочитое дробление в случае сильной парцелляции акцентирует важнейшие элементы сообщения (правительство ожидает содействия, а не пассивности; русского человека называют плутом (что возмущает автора), российская общественность обладает тощей логикой - что имеет далеко идущие последствия).

Особым случаем сильной парцелляции следует считать разрыв предикативной основы предложения: Франиузскій, Германскій, Русскій народ - предполагают землю, на которой возникло и с которою органически связалось народное гражданское бытіе (А: 88); дорожим всяким признаком жизни [...] в нашем обществе [...], котораго единственным до сих пор двигателем было - начальство (А: 100); всть ошибки в ея <Пруссии > политикьв внутренней-происходят именно от союза и согласія в воззртніях ея правительства с Русским (А: 116).

Подобное членение предложения должно быть связано с коммуникативным намерением говорящего - возможно, так автор удерживает читательское внимание.

Завершая анализ употреблений «тире» в текстах русской периодической печати XIX в., можем констатировать, что применение этого знака обусловливалось необходимостью логико-смыслового выделения отдельных фрагментов 
целостного текста, а также имело специфическую семасиологическую сторону - значимость тире как маркера «молчания», за которым последует важная информация, «новое слово» - новость, мнение, точка зрения.

Таким образом, знак «тире» в качестве графического средства передачи сообщения по сути сам становится сообщением. Активное использование тире в текстах новостного, полемического и критико-аналитического характера, как показывают рассмотренные примеры, демонстрирует справедливость утверждения относительно обилия авторских знаков препинания в русской письменной речи: «Русское мышление в противоположность западному как бы все время пытается субъектизировать речь, вылавливая [...] все особое и специфическое вплоть до интонации» [Rossman 2003: 75]. Отмеченная диалогичность текстов, подкрепленная использованием тире, создает особую медиареальность, характеризующуюся специфическим коммуницированием «автора» и «читателя».

\section{Источники}

A: Polnoe sobranie sočinenij I.S. Aksakova. Vol. 3: Stat’i iz «Dnâ», «Moskvy», «Moskviča» $i$ «Rusi», 1886, Moskva: Tip. M.G. Volčaninova.

B: Biblioteka dlâ čteniâ: žurnal slovesnosti, nauk, hudožestv, promyšlennosti, novostej i mod, 1844, vol. 64 .

CM: Severnyj Muravej: gazeta promyšlennosti, 1830, vol. I.

\section{Литература}

Boduèn de Kurtene I.A., 1963, Znaki prepinaniâ [in:] I.A. Boduèn de Kurtene, Izbrannye trudy po obŝemu âzykoznanîu, vol. 2, Moskva: Izdatel'stvo Akademii nauk SSSR, pp. 237-240.

Dibrova E.I., 1998, Kategorii hudožestvennogo teksta [in:] Semantika âzykovyh edinic, vol. 2, Moskva: Sportakadempress, pp. 250-257.

Kireevskij I.V., 1911, Obozrenie sovremennogo sostoâniâ literatury. Stat'â 1 [in:] M. Geršenzon (ed.), Polnoe sobranie sočinenij I.V. Kireevskogo, vol. 1, Moskva: Tip. Imp. Mosk. un-ta, pp. 121-144.

Orehova N.N., 2000, Punktuaciâ i pis'mo (na materiale russkogo i anglijskogo âzyka), Iževsk: Izdatel'skij dom «Udmurtskij universitet».

Rossman V., 2003, Tehniki punktuacii: znak prepinaniâ kak filosofskij metod, Voprosy filosofii, 4, pp. 68-76.

Samarcev O.R., 2007, Tvorčeskaâ deâtel'nost'žurnalista: očerki teorii i praktiki, Moskva: Akadem. proekt.

Skovorodnikov A.P., 1978, O klassifikacii parcellirovannyh predloženij v sovremennom russkom literaturnom âzyke, Filologičeskie nauki, 2, pp. 58-67.

Skripčenko D.V., 2016, Status sobytiâ v prostranstve mass-media: dis. k. filos. n., Sankt-Peterburg. 
Švarckopf B.S., 1988, Sovremennaâ punktuaciâ: sistema i ee funkcionirovanie, Moskva: Nauka.

Švarckopf B.S., 1997, Tire [in:] Û.N. Karaulov (ed.), Russkij âzyk: ènciklopediâ. $2^{\text {nd }}$ ed., Moskva: Bol'šaâ ros. èncikl;; Drofa, p. 562. 